\title{
Aquifer parameter identification and interpretation with different analytical methods
}

\author{
Mehmet E Birpinar \\ Yildiz Technical University, Civil Engineering Faculty, Hydraulics Division, Yildiz 80750, Istanbul, Turkey
}

\begin{abstract}
Aquifer tests yield estimations of hydrogeological parameters through suitable analytical models from field data recorded as drawdown variations by time or distance. In practice, most often a single model is adopted with a set of assumptions, and unfortunately, field data deviations from the model type curves are not considered in interpretations. This is a rather mechanistic approach which implies assumptions that the aquifer is geologically homogeneous and isotropic. Such an approach cannot be true because within the aquifer test area there may appear heterogeneities and anisotropies which hinder the application of a single model. It is, therefore, necessary to try several available models for the same aquifer test data, in order to extract pos sible variabilities in hydrogeological parameters. Such an extensive study can only be done when there is a set of aquifer test data with main and observation wells at different distances and directions.

This paper presents an analysis of an aquifer test in a thick alluvial valley in Pakistan. The aquifer consists of extremely heterogeneous sediments. Different approaches including the Theis, Jacob, Hantush, and Singh analytical nodels, are used to analyse the drawdown data from several observation wells.
\end{abstract}

Keywords: aquifer parameter, transmissivity, storage coeficient, aqufer tests, analytical methods

\section{Introduction}

Movement and abstraction of groundwater in the geological formations are dependent on the hydrogeological parameters of the aquifers. The purpose of any aquifer test is to determine the hydrogeological parameters. Among the basic parameters are the storativity, transmissivity and leakage coefficients. The hydrogeological parameters are hidden in the field test data and their identification is possible using the available of physically plausible models suitable for the prevailing field circumstances. Evaluation of aquifer parameters, namely, transmissivity $\mathrm{T}$, and storage coefficient $S$, from aquifer test data has been a continual field research. Several conventional and computer-based methods are available for analysing (Kruseman and De Ridder, 1991). Due to a different set of assumptions on each method, the hydrogeological parameter estimates are quite different from each other. Efforts have been made to develop simple calculation methods for aquifer parameters since Cooper and Jacob (1946) proposed their simple and widely used method. The main limitation of this method is that the dimensionless time factor, $u$, should be less than 0.01 . However, according to Singh (2000) it cannot be applied to estimate aquifer parameters when most of the data have $u>0.01$. On the other hand, the curve-matching method proposed by Theis (Lohman, 1972) involves much subjectivity in judging the best match between the observed and theoretical curves, especially when only early drawdowns are considered (Singh, 2000). Furthermore, Sen (1987) proposed a unique storage coefficient determination approach for large diameter wells which experience steady or quasi-steady groundwater flow conditions. The application of the method does not require any complicated mathematical procedure as in the classical-type curve matching procedures. This method becomes

P (90) $2122597070 \times 2453$; fax: (90) 2122596762 ;

e-mail: birpinar@yildiz.edu.tr

Received 1 Juty 2002; accepted in revised form 14 April 2003. very effective when it is coupled with the Theim (1906) formula. Singh (2000) proposed a simple method for explicit determination of confined aquifer parameters from early drawdown data. This method makes use of a few early drawdown data at an observation well and yields accurate values of confined aquifer parameters with no curve matching requirement. The method converges to the Cooper-Jacob method for late drawdown data. Application of the method on published data sets shows that the estimates of the aquifer parameters using only a few initial drawdowns are as good as those obtained by Theis curve matching when all data, including the late drawdowns $(u<0.01)$, are used. Singh (2001a) has also proposed another robust optimisation method for the calculation of aquifer parameters from shorter duration aquifer test data when there is an impervious boundary. Another simple method that uses the temporal derivative of drawdowns was proposed for the explicit evaluation of confined aquifer parameters utilising the early drawdowns (Singh, 2001b). The method uses an analytical approach to calculate the temporal derivative of drawdowns. The method can analyse the drawdown data on multiple observation wells taken together to obtain averaged aquifer parameters. The method was applied to published data sets and results were compared with the traditional methods already available in the literature. Singh (2002) proposed another simple method for the identification of confined aquifer parameters and effective distance to either an impermeable boundary or a recharge from the drawdowns observed at an observation well due to pumping at a constant rate.

This paper concentrates on a significant issue with regard to the interpretation of aquifer tests, i.e. ensuring meaningful interpretations. This issue commonly arises from the use of computer programs to interpret aquifer test data which generally leads to misinterpretations. The objective of any software is to create the best match of the time-drawdown data regardless of the suitability of the analytical model to the hydrogeological setting. Hence, there are several pitfalls involved in employing commonly used computer programs and mechanistic-type curve fittings without 


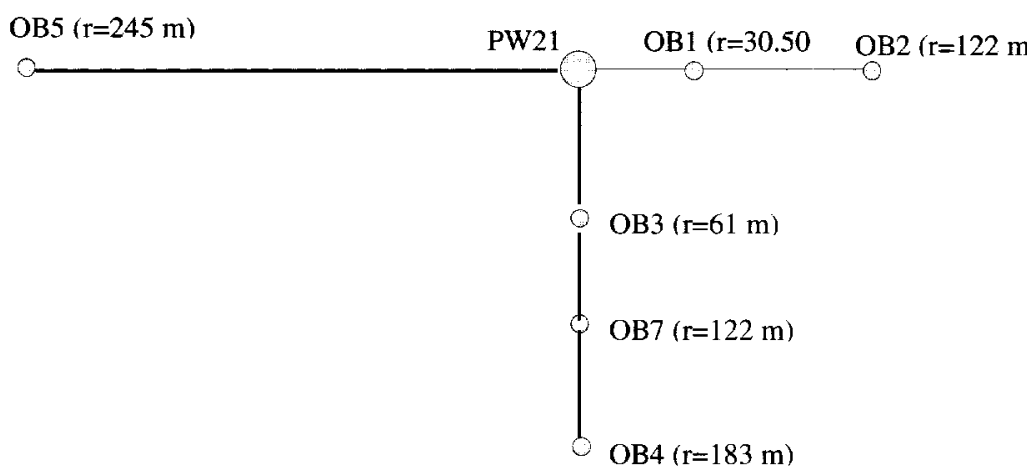

Figure 1

Plan view of $P W$ and observation wells at $C T W-21$
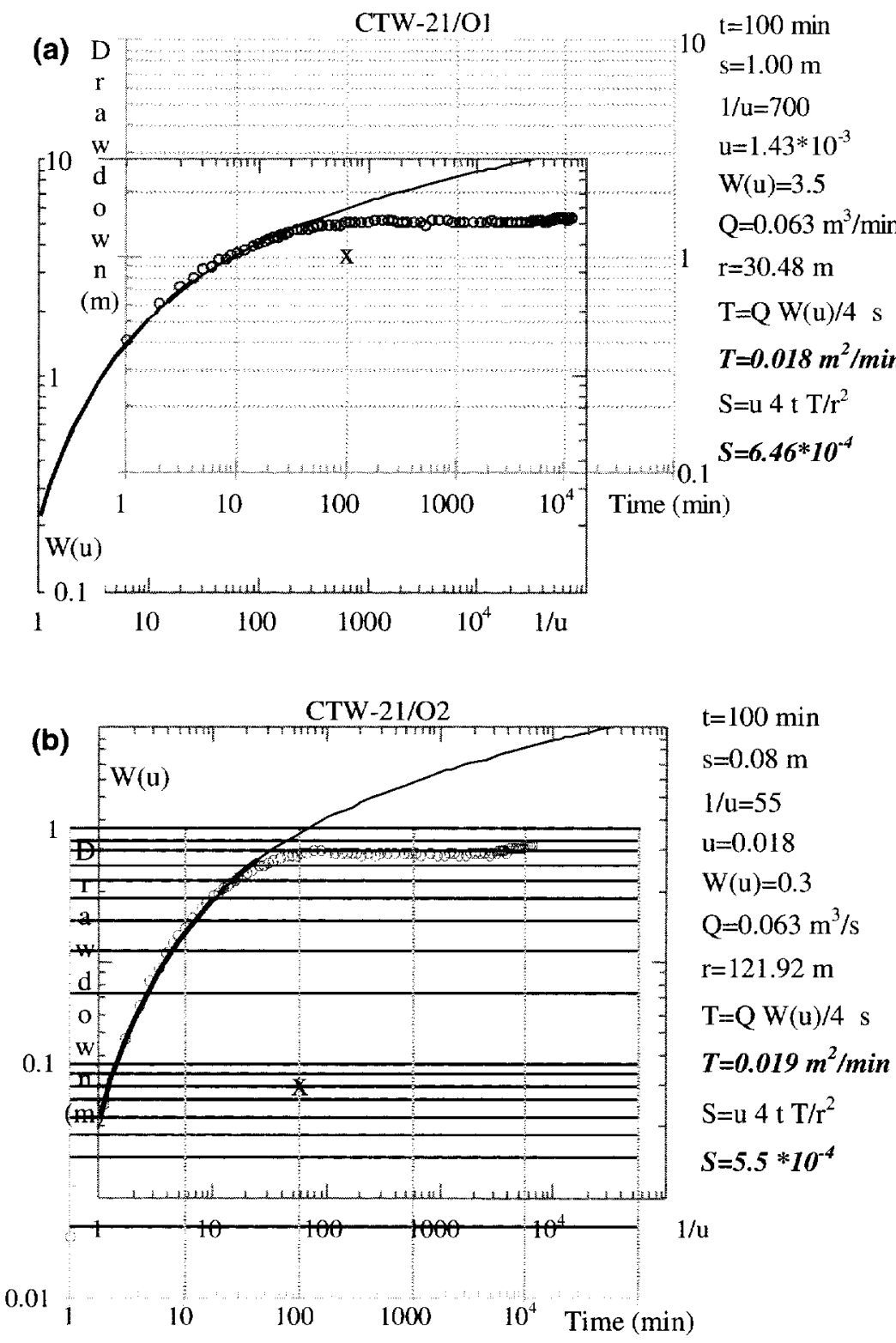

Figure 2

Theis type curve matching (a) OB1; (b) $O B 2$ consideration of the hydrogeological setting and without employing multiple assessments of the aquifer test data. In the following sequel, almost all of the suitable classical (Theis, 1935; Jacob, 1940; Hantush, 1956) and dimensionless straight-line (Sen, $1990 ; 1995)$ methods are employed for qualitative and quantitative interpretations as presented by Ahmad (1998).

It is the purpose of this paper to discard the use of a single analytical model use to determine aquifer parameters. Hence, several analytical models are applied to aquifer test data in the Chaj Doab area in Pakistan with the explanation of deviations from the model-type curves. Finally, a new method is proposed to calculate the radius of influence.

\section{Study area description}

The main reason for selecting the Chaj Doab area in Pakistan was the availability of extensive aquifer test data. As shown in Fig. 1, there are 6 observation (OB) wells drilled at different distances and directions from the pumping well (PW). The dominant geological unit in the study area is Quaternary alluvium. This alluvium has been deposited on a base of igneous and metamorphic rocks of Precambrian age or on semi-consolidated Tertiary rocks as described by Kidwai (1963). The unconsolidated alluvial complex consists of sand, silt, clay and gravel in different proportions depending on the environmental forces involved in the depositing agency. Environmental forces here mean slopes of the ancestral streams, barriers faced by them, the amount of water and sediments moving together in those streams and the climates of the source areas. The deposits of the area are of highly heterogeneous nature with little horizontal or vertical continuity. Interfingering lenses of silty clay with sands are widespread in the region. The thickness of the alluvium is not known accurately. Only alluvium has occurred in the exploratory test holes drilled to maximum depth of $500 \mathrm{~m}$. Kidwai (1963), Arif (1966) and Chaudhry (1966) have described the alluvium of the area as acting as an overall unconfined aquifer. The subsurface geological composition indicates the unconfined nature of the aquifer with abundance of clayey deposits in the area. Interpretation of these sections in terms of hydrostratigraphy gives enough clues to conclude that the hydrogeological unit in the study area is composed of different types of aquifer. This view is supported by the conversion of geological logs of observation wells at pumping test sites into hydrostratigraphic units and then, finally, to the nearest counterpart in the form of aquifer, aquitard and aquiclude, (Ahmad, 1998)

For the identification of aquifer parameters in the Chaj Doab area of Pakistan, pumping tests were performed at different locations to get the representative coverage of the area. Time-drawdown data of pumping and recovery phases were recorded both in the main and observation wells simultaneously. These pumping tests were carried out by WASID 
(Water and Soil Investigation Division) of WAPDA (Water and Power Development Authority) in Pakistan (WAPDA, 1983. Although all the aquifer test data are treated with different analytical methods, for the sake of brevily, only the aquifer test data set recorded at site CTW-21 are presented in detail.

\section{Analytical models and interpretations}

The pumping test at CTW-21 site was performed for an 8-day duration starting from 17 September 1959 at 10:00 local time to 25 September 1959 at 10:00. The pumping rate of water withdrawal from the PW was fixed at $0.0629 \mathrm{~m}^{3} / \mathrm{s}$.

On the basis of inferences depicted from the qualitative analysis of the time-drawdown data collected during the pumping and recovery phases, the aquifer has been identified as having combined characters of confined, leaky and unconfined behaviours. As this does not qualify solely for any known category of aquifer, therefore, the quantitative evaluations of the hydrogeological parameters such as transmissivity $T$, storage coefficient $\mathrm{S}$, hydraulic conductivity $\mathrm{K}$ and leakage factor $\mathbf{L}$, are possible after the acceptance of a considerable error amount with available analytical techniques. Therefore, the hydrogeological parameters are estimated by using different techniques available in the literature for overall unconfined aquifer and leaky aquifers.

Transmissivities and storage coefficient estimates by means of the Theis method are shown in Figs. $2 \mathrm{a}$ and $\mathrm{b}$ as an example and the results for all observation wells are presented collectively in Tables 1 and 2. It is obvious that all the $\mathrm{OB}$ wells exhibit the transmissivities approximately in the same range of $0.02 \mathrm{~m} / \mathrm{s}$. As in Fig. 2 only initial portions of time-drawdown graphs on log-log scale match with initial and moderate parts of the Theis curve. On the other hand, storage coefficients appear in the range of $10^{-4}$. Therefore, after about one hour of constant pumping, the aquifer
TABLE 1

Estimated transmissivity values from the various methods for the selected data

\begin{tabular}{|c|c|c|c|c|c|c|c|c|}
\hline \multirow{2}{*}{$\begin{array}{c}\text { Well } \\
\text { number }\end{array}$} & \multirow{2}{*}{$\begin{array}{c}\begin{array}{c}\text { Distance } \\
\text { from the } \\
\text { pumping } \\
\text { well }\end{array} \\
r(m)\end{array}$} & \multirow{2}{*}{$\begin{array}{c}\begin{array}{c}\text { Theis } \\
\text { method }\end{array} \\
T_{T h}\end{array}$} & \multicolumn{3}{|c|}{ Jacob methods } & \multicolumn{2}{|c|}{ Hantush methods } & \multirow{2}{*}{$\begin{array}{c}\begin{array}{c}\text { Singh } \\
\text { method } \\
(2000)\end{array} \\
T\end{array}$} \\
\hline & & & $T_{\text {J(dd-t) }}$ & $\mathbf{T}_{\mathrm{J}(\mathrm{dd}-\mathrm{r})}$ & $T_{J(d d-U r 2)}$ & $T_{H J}$ & $T_{\mid P}$ & \\
\hline P21 & - & - & - & - & - & - & - & - \\
\hline Gl & 30.48 & 0.018 & 0.019 & & 0.021 & 0.016 & 0.018 & - \\
\hline G2 & 121.92 & 0.019 & 0.024 & & 0.026 & 0.029 & 0.017 & 0.0160 \\
\hline G3 & 60.96 & 0.020 & 0.021 & 0.021 & 0.021 & 0.026 & 0.017 & 0.0110 \\
\hline G4 & 182.88 & 0.022 & 0.033 & & 0.036 & 0.057 & 0.019 & 0.0216 \\
\hline G5 & 243.84 & 0.020 & 0.033 & & 0.034 & 0.064 & 0.018 & 0.0204 \\
\hline G7 & 121.92 & 0.020 & 0.024 & & 0.025 & 0.036 & 0.015 & 0.0140 \\
\hline \multicolumn{2}{|c|}{ Aquifer mean } & 0.020 & 0.026 & 0.021 & 0.027 & 0.038 & 0.017 & 0.0170 \\
\hline
\end{tabular}

TABLE 2

Estimated storage coefficient values from the various methods for the selected data

\begin{tabular}{|c|c|c|c|c|c|c|c|c|}
\hline \multirow{2}{*}{$\begin{array}{l}\text { Well } \\
\text { number }\end{array}$} & \multirow{2}{*}{$\begin{array}{c}\begin{array}{c}\text { Distance } \\
\text { from the } \\
\text { pumping } \\
\text { well }\end{array} \\
r(m)\end{array}$} & \multirow{2}{*}{$\begin{array}{c}\begin{array}{c}\text { Theis } \\
\text { method }\end{array} \\
\mathrm{S}_{\mathrm{Th}}\end{array}$} & \multicolumn{3}{|c|}{ Jacob methods } & \multicolumn{2}{|c|}{ Hantush methods } & \multirow{2}{*}{$\begin{array}{c}\begin{array}{c}\text { Singh } \\
\text { method } \\
(2000)\end{array} \\
\mathrm{s}\end{array}$} \\
\hline & & & $\mathbf{S}_{\mathrm{J}(\mathrm{dd}-\mathrm{t})}$ & $S J_{(d d-r)}$ & $\mathbf{S}_{\left(d d-t / r^{2}\right)}$ & $\mathbf{S}_{\mathrm{H}-J}$ & $S_{I P}$ & \\
\hline Gl & 30.48 & $6.5 \div 10^{-4}$ & $5.6 * 10^{-4}$ & & $5.6^{*} 10^{-4}$ & $7.5 * 10^{-4}$ & $6.2 * 10^{-4}$ & - \\
\hline G2 & 121.92 & $5.5 \div 10^{-4}$ & $3.9 * 10^{-4}$ & & $4.1 * 10^{-7}$ & $3.3 * 10^{-4}$ & $4.9^{*} 10^{-4}$ & $5.2 * 10^{-4}$ \\
\hline G3 & 60.96 & $6.2 * 10^{-4}$ & $4.6^{*} 10^{-4}$ & $5.3^{*} 10^{-4}$ & $4.5^{*} 10^{-4}$ & $2.8 * 10^{-4}$ & $4.3 * 10^{-4}$ & $6.2 * 10^{-4}$ \\
\hline G4 & 182.88 & $6.8 * 10^{-4}$ & $4.6 * 10^{-4}$ & & $4.9^{*} 10^{-4}$ & $8.2 * 10^{4}$ & $6.1 * 10^{-4}$ & $5.2 * 10^{-4}$ \\
\hline G5 & 243.84 & $6.7 * 10^{-4}$ & $4.1 * 10^{-4}$ & & $4.1 * 10^{-4}$ & $1.1 * 10^{-1}$ & $5.0^{*} 10^{-4}$ & $5.7 * 10^{-4}$ \\
\hline G7 & 121.92 & $6.7 * 10^{-4}$ & $4.4^{*} 10^{-4}$ & & $5.1^{*} 10^{-4}$ & $2.4 * 10^{-4}$ & $5.5 * 10^{-4}$ & $6.7 * 10^{-4}$ \\
\hline \multicolumn{2}{|c|}{ Aquifer mean } & $6.4 * 10^{4}$ & $4.5 * 10^{-4}$ & $5.3^{*} 10^{4}$ & $4.0^{*} 10^{-4}$ & $4.2^{*} 10^{-4}$ & $5.3 * 10^{-4}$ & $5.8 * 10^{-4}$ \\
\hline
\end{tabular}

Note: Length unit is meter and time unit is second. 
(a)

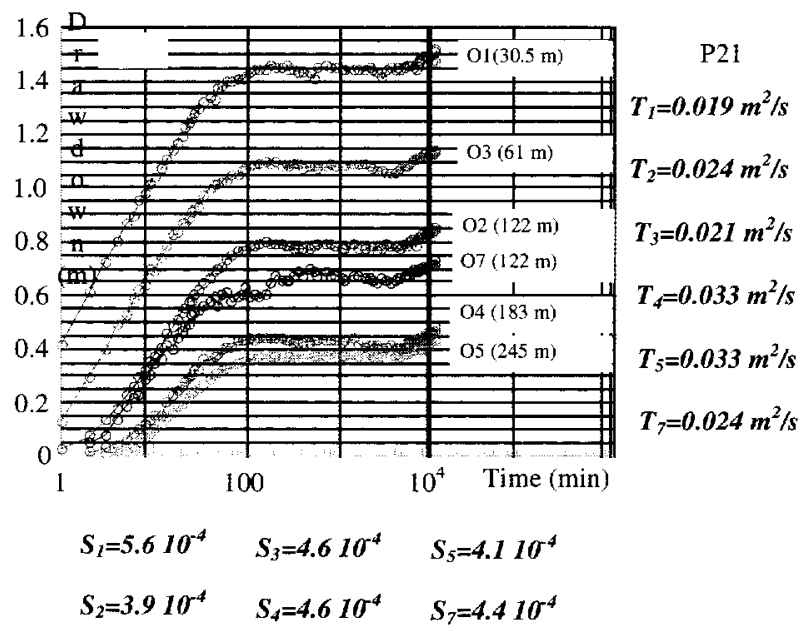

(b)

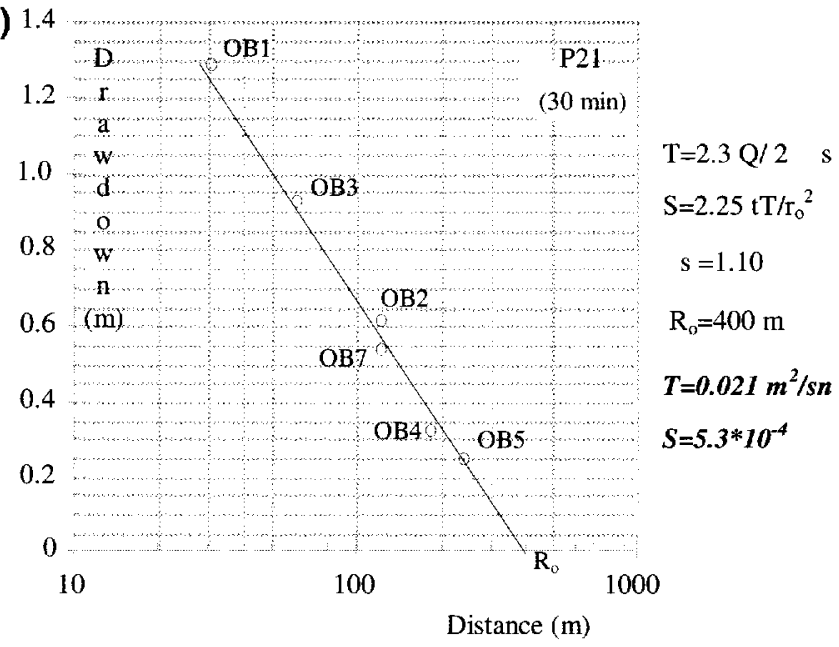

Figure 3

Application of Jacob straight line methods (a) time-drawdown, (b) distance-drawdown

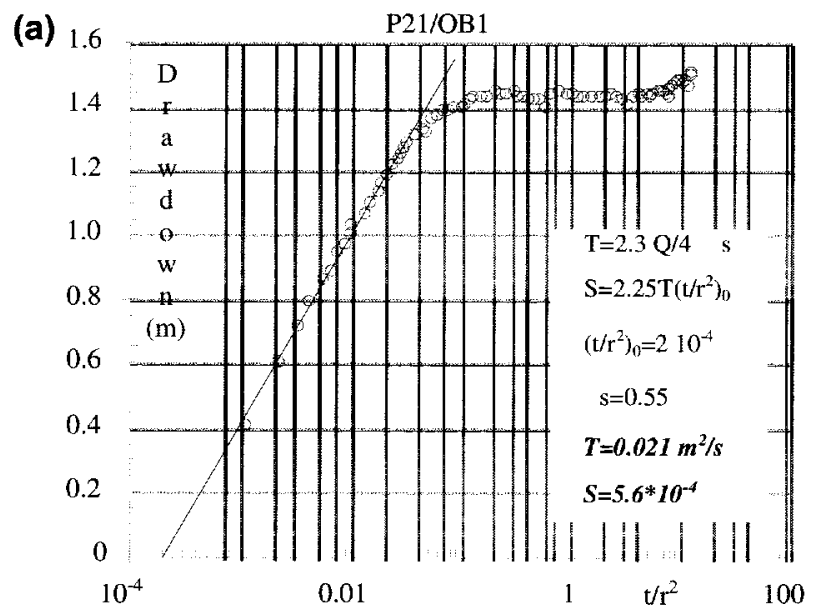

(b)

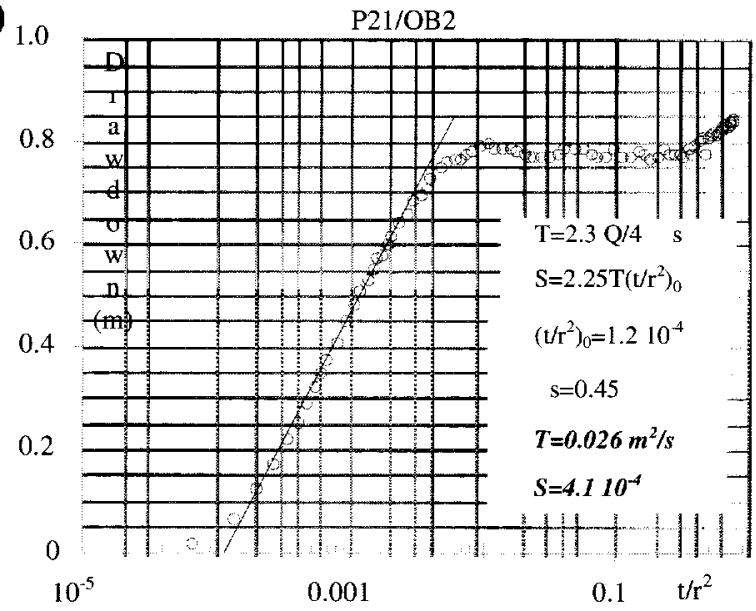

Figure 4

Application of Jacob drawdown-t/ $r^{2}$ method (a) OB-1, (b) OB-2

increasing values of transmissity as the distance of the $O B$ wells increases from the PW. It may be because of the change in hydraulic gradient within the radius of influence. The hydraulic gradient is maximum near the PW and minimum at the periphery of the depression cone. As one moves towards the centre of the depression cone, the change in hydraulic gradient increases too. Although on the time-drawdown semilogarithmic graph, the hydraulic gradient does not appear explicitly, it affects the drawdowns measured at different distances from the PW implicitly.

The same data are also used for the Jacob distance-drawdown method. Hence, a single value of transmissivity emerges as 0.021 $\mathrm{m}^{2} / \mathrm{s}$, but a further property of this method is that it also gives the value of radius of influence which in the present case is $400 \mathrm{~m}$. The radius of influence has a definite physical significance because at the time of exploitation, it helps in selecting the locations of the production wells to prevent any interference. Storage coefficients deduced from both Jacob methods are shown in Table 2 with their range between $3.9 \times 10^{-4}$ to $5.6 \times 10^{-4}$. Although the time-drawdown Jacob method gives as many storage coefficient values as there are number of observation wells, the distance-drawdown method reveals only one value of storage coefficient which is $5.3 \times 10^{-4}$. The Jacob distance-time-drawdown (Fig. 4 a; b) method has also been applied to the same data set for each of the observation wells. The results of $T$ and $S$ for this method have been given in Tables 1 and 2 collectively.

As the time-drawdown plots on semi-logarithmic scale (Fig. 3a) for the total time length depict steady state after about $100 \mathrm{~min}$ of pump start-up, the aquifer can be considered as leaky. For the determination of hydrogeological parameters such as transmissivity $T$, storage coefficient $S$ and leakage factor $L$, of the aquifer under study, Hantush-Jacob (1955) and Hantush inflection point methods are applied and the results are shown in Tables 1 and 2 with the relevant graphs in Figs. $5 \mathrm{a}$ and $\mathrm{b}$, respectively. The Hantush-Jacob method is a type curve matching model in which a curve having an $\mathrm{r} / \mathrm{L}$ value equal to 0.1 is used, because curves with higher $r / L$ values are not found in the available literature. Transmissivities calculated with this method range between 0.016 and $0.064 \mathrm{~m}^{2} / \mathrm{s}$ whereas the storage coefficients are of the order of $10^{-4}$ and lie in the acceptable range. The Hantush inflection point method reveals transmissivity values in the range between 0.015 and $0.019 \mathrm{~m}^{2} / \mathrm{s}$. The variation 
among the transmissivities evaluated with the Hantush inflection point method is very small compared to the Hantush-Jacob method.

The same data set for the observation wells is also applied to the Singh (2000) analytical method. Values of $s / t$ (drawdown/ time) were plotted against $t$, and the peak was located by drawing a smooth curve through the plotted points for each selected case (Fig. 6). The results of transmissivity and storage coefficient values are given in Tables 1 and 2 for all the observation wells. The transmissivity values are in the range of 0.014 to $0.022 \mathrm{~m}^{2} / \mathrm{s}$ with the storage coefficients of the order of $10^{-4}$.

\section{Conclusions}

In practice, most often aquifer tests are applied mechanically without consideration of the deviations between the field data and the available type curves. It has been shown in this paper that a single analytical model cannot yield meaningful interpretations, and therefore, in order to take into account possible aquifer heterogeneity and anisotropy features, several convenient analytical models have been applied, each with supplementary interpretations. Various analytical methods have been applied to the Chaj Doab area (Pakistan) aquifer tests supported by qualitative interpretations for deviations from the available type curves or straight lines.

In addition to classical analytical models such as the Theis, Jacob and Hantush type curves, the Singh (2000) analytical method has also been applied. The combined application of all these methods with qualitative interpretations extract the maximum possible information from given field data.

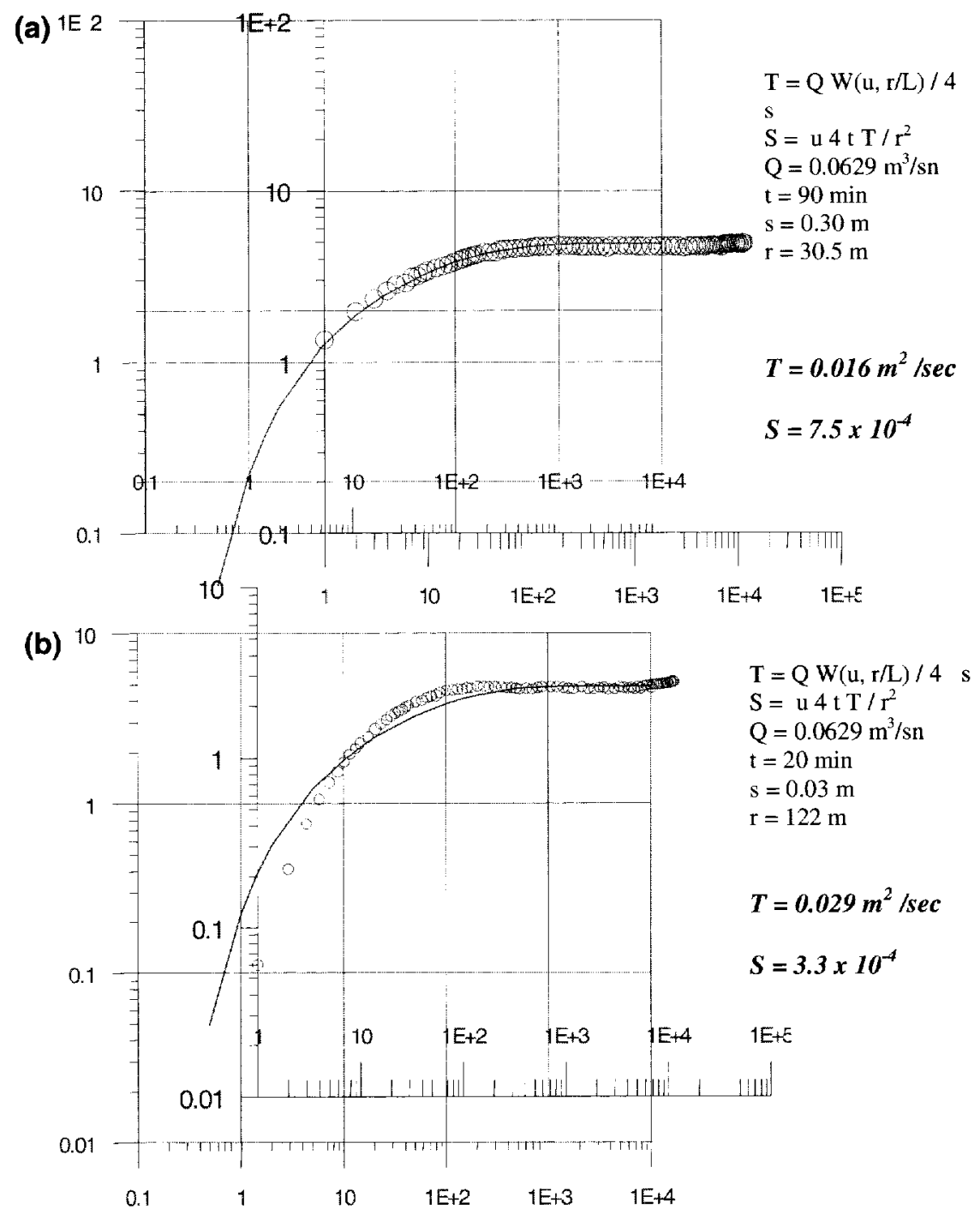

Figure 5

Hantush-Jacob type curve matching to field data (a) OB-1 (b) OB-2
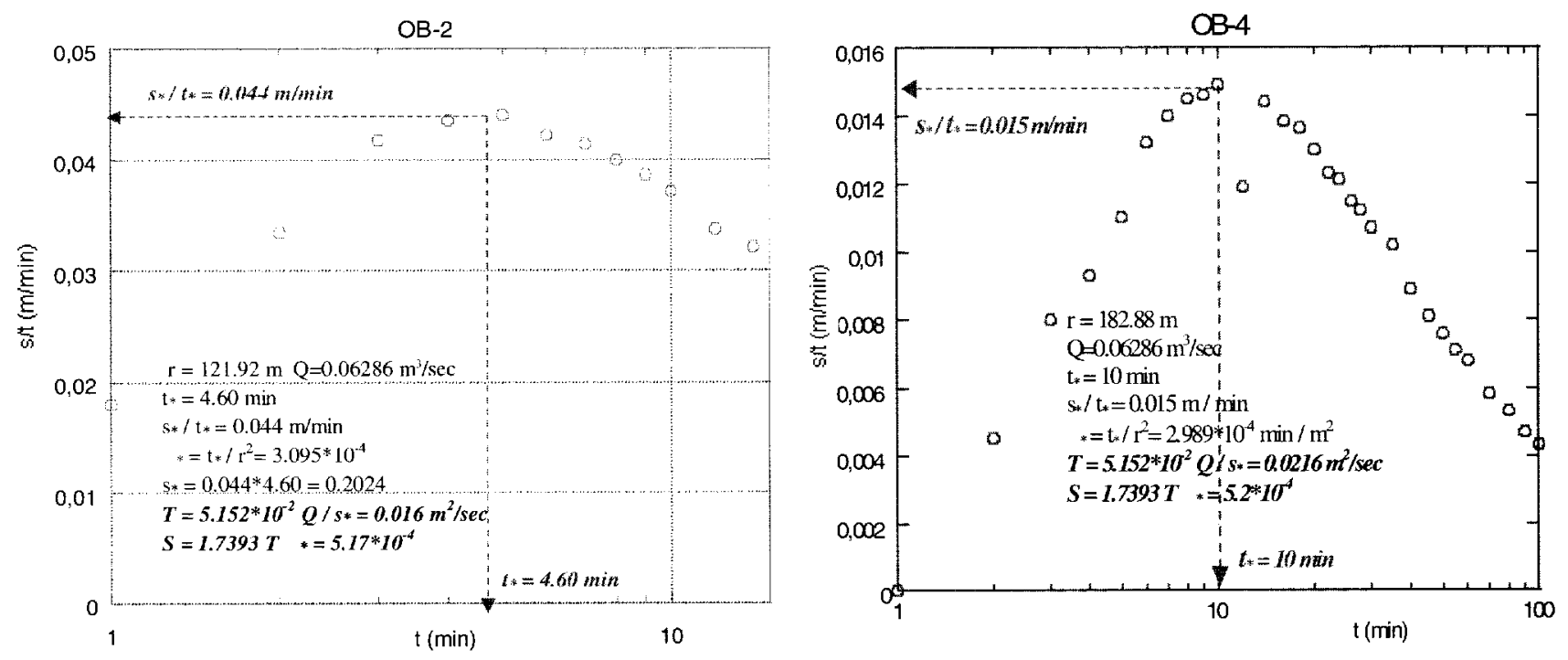

Figure 6

Application of Singh (2000) method (a) OB-2, (b) OB-4 


\section{References}

AHMAD N (1998) Evaluation of Groundwater Resources in the Upper Middle Part of Chaj Doab Area, Pakistan. Unpublished Ph.D. Thesis, Technical University of Istanbul. $308 \mathrm{pp}$

ARIF AH (1966) Analysis of Selected Tests of Aquifer Characteristics, Pakistan. Wasid Pub. 45 25-60.

CHAUDHRY AR (1966) Analysis of hydrologic performance tests in unconfined aquifers. Tech. Paper No. 14, Water and Power Development Authority, Water and Soil Investigation Division, Pakistan. 3-53.

COOPER HH and JACOB CE (1946) A generalized graphical method for evaluating formation constants and summarizing well field history. Trans. Am. Geophys. Union 27 526-534.

HANTUSH MS (1956) Analysis of data from pumping tests in leaky aquifers. Trans. Am. Geophys. Union 37 702-714.

HANTUSH MS and JACOB CE (1955) Non-steady radial flow in an infinite leaky aquifer. Trans. Am. Geophys. Union 36 95-100.

JACOB CE (1940) On the flow of water in an elastic artesian aquifer. $A m$. Geophys. Un. Trans. 72574.

KRUSEMAN GP and DE RIDDER NA (1991) Analysis and Evaluation of Pumping Test Data. ILRI Publ. 47, ${ }^{\text {nd }}$ Ad., Wageningen, The Netherlands.

KIDWAI ZU (1963) Geology of Rechna and Chaj Doab West Pakistan. Water \& Soils Invest. Div. Bull. 5 16-20.
LOHMAN LW (1972) Ground-Water Hydraulics. U.S. Geological Survey Profl. Paper 708.

SINGH SK (2000) Simple method for confined-aquifer parameter estimation. J. Irrig. and Drainage Eng., ASCE 126 (6) 404-407.

SINGH SK (2001a) Identifying impervious boundary and aquifer parameters from pump test data. J. Hydraul. Eng., ASCE 127 (4) 280-285.

SINGH SK (2001b) Confined aquifer parameters from temporal derivative of drawdowns. J. Hydraul. Eng., ASCE 127 (6) 466-470.

SINGH SK (2002) Aquifer boundaries and parameter Identification Simplified. J. Hydraul. Eng., ASCE 128 (8) 774-780.

SEN Z (1987) Storage coefficient determination from quasi-steady state flow. Nordic Hyatrol. 18 101-110.

SENZ (1990) Dimensionless straight type lines for aquifer test. J. Hydraul. Eng., ASCE 116 (9) 1145-1156.

SEN Z (1995) Applied Hydrogeology for Scientists and Engineers. CRC, Lewis Pub. New York. 161-299.

THEIS CV (1935) The relation between the lowering of the piezometric surface and the rate and duration of discharge of a well using groundwater storage. Trans. Am. Geophys. Union 2 519-524.

THEIM G (1906) Hydrologische Methoden. J.M. Gebhart, Leipzig. 56.

WAPDA (1983) Hydrogeological Data of Chaj Doab. Vol. II, Basic Data Release No. 9. Directorate General of Hydrogeology, WAPDA, Lahore, Pakistan. 15-50. 